CARADDE: Jurnal Pengabdian Kepada Masyarakat
$\begin{gathered}\text { https://journal.ilininstitute.com/index.php/caradde } \\ \text { Volume 2 | Nomor 2 | Februari | 2020 } \\ \text { e-ISSN: 2621-7910 dan p-ISSN: 2621-7961 }\end{gathered}$
DOI: https://doi.org/10.31960/caradde.v2i2.256

\title{
Program Abdimas KWT Kenanga Desa Gunung Salak, Kecamatan Selemadeg Timur Kab Tabanan
}

\section{Ni Putu Sukanteri ${ }^{1}$, Putu Fajar Kartika Lestari ${ }^{2}$, I Made Suryana ${ }^{3}$}

\begin{tabular}{ll}
\hline \hline Keywords : & Tujuan pelaksanaan pengabdian pada KWT Kenanga di Desa \\
Program Abdimas; & Gunung Salak Kecamatan Selemadeg Barat Kabupaten Tabanan \\
KWT; & yaitu untuk pemanfaatan lahan pekarangan yang belum optimal \\
kenanga, & sebagai lahan penghasil pangan keluarga, meningkatkan kualitas \\
gunung salak & sumber daya manusia terutama wanita tani dalam upaya \\
& mengolah hasil pertanian menjadi produk olahan industri rumah \\
Corespondensi Author & tangga agar produk memiliki nilai tambah serta memperluas \\
1,2)Prodi Agribisnis, ${ }^{33}$ Prodi Agrotek, & penguasaan pemasaran produk industri KWT Kenanga. Untuk \\
Fakultas Pertanian, Universitas & meningkatkan manajema pengelolaan kelompok dalam bidang \\
Mahasaraswati Denpasar & administrasi. Metode abdimas yaitu melalui survei dan sosialisasi \\
Email : putusukanteri@gmail.com & dilanjutkan memberikan pelatihan dan pendampingan kelompok \\
& industri rumah tangga secara intensif sampai menghasilkan \\
& produk yang siap jual dan berkualitas. Pelaksanaan program \\
& abdimas menunjukkan setelah dilaksanakan pendampingan dan \\
& pelatihan terdapat peningkatan obilitas kelompok meliputi \\
History Artikel & keaktifa anggota dalam mengembangkan kegiatan kelompok, \\
Received: $31-J u l i-2019 ;$ & manajemen administrasi telah tertata dengan baik, anggota \\
Reviewed: 17-Agustus-2019; & kelompok menguasai cara mengolah produk pasca panen, \\
Accepted: 09-Oktober-2019; & peningkatan intensitasi pertemuan dalam bentuk kegiatan arisan \\
Avalaible Online: 16-Desember-2019; & rutin bulanan, memanfaatkan lahan kelompok dengan \\
Published: 04-Februari-2020; & meningkatkan jumlah komoditas usahatani yang dikembangkan \\
& agar mampu menghasilkan variasi pengolahan produk KWT \\
& Kenanga.
\end{tabular}

(1) This work is licensed under a Creative Commons Attribution 4.0 International License

\section{PENDAHULUAN}

KWT Kenanga merupakan kelompok wanita tani yang terdapat di Desa Gunung salak, kecamatan Selemadeg Timur Kabupaten Tabanan. KWT Kenanga merupakan kelompok wanita tani yang aktif dalam kegiatan produksi dan pengolahan hasil pertanian lokal yang dihasilkan dari lahan di wilayah Gunung Salak. Pemberdayaan KWT Kenanga sangat dibutuhkan karena di wilayah Desa Gunung Salak terdapat berbagai hasil pertain yang melimpah seperti Talas, Ketela Pohon, Padi, Kakao, Pisang dan hasil buah -buahan yang panen mada musim-musim tertentu. Kebergagaman hasil pertanian menyebabkan kesulitan pemasaran bahkan pada saat panen raya maka harga hasil pertanian menjadi 
Caradde: Jurnal Pengabdian Kepada Masyarakat Vol 2 No 2, Februari 2020

rendah. Kondisi inilah yang menginspirasi KWT Kenanga untuk mengupayakan agar hasil pertanian dapat dipasarkan dengan cara yang lebih baik dan tentunya mendapat harga lebih tinggi. KWT Kenang di Desa Gunung Salak merupakan sentra produksi padi di kecamatan selemadeg Timur sehingga hasil padi sangat melimpah dan mempunyai potensi yang besar sebagai penghasil produk olahan beras, ubi jalar, singkong dan keladi kuning yang dapat di olah menjadi berbagai jenis makanan olahan produk lokal sebagai ikon Desa Gunung Salak (Sutjirta, 2015).

KWT Kenanga di Desa Gunung Salak merupakan KWT yang berada di kawasan Destinasi Desa Wisata sehingga potensi untuk mengembangkan usaha agribisnis sangat besar. Berdasarkan potensi yang dihasilkan dalam bidang pertanian KWT kenanga layak mendapatkan pelatihan maupun pendampingan karena terdapat pengunjung yang telah berkunjung ke desa wisata gunung salak menjadikan KWT Kenanga sebagai penyedia jasa kuliner di kawasan desa wisata tersebut. Menurut Surat Edaran Kepala Badan Pendidikan dan Latihan Pertanian Nomor. K/LP.620/147/X/92k, tanggal 8 Oktober 1992 tentang Pedoman Umum Pembinaan Wanita Tani-Nelayan, yang dimaksud wanita tani adalah kaum wanita yang berstatus selaku petani- nelayan yang wanita (ibu, anak, mertua, kemenakan, dan lain-lain) (Suwitaningrum, 2013).

Wanita tani memiliki peranan penting dalam pengelolaan usaha tani termasuk usaha pengolahan hasil pertanian. Selaian dalam bidang pemberdayaan mengutamakan usaha sendiri dan orang yang diberdayakan untuk meraih keberdayaannya. Oleh karena itu pemberdayaan sangat jauh dari konotasi ketergantungan (Saptaningsih, dkk 2009).

Harapannya KWT Kenanga mampu beroperasi sebagai bisnis indutri rumah tangga dalam memperdayakan pangan lokal sebagai bahan baku indurstri dan menciptakan nilai tambah produk.

Peranan Kelompok Wanita Tani Perdesaan Dalam Menunjang Pendapatan Keluarga" mendskripsikan bahwa, proses produksi dalam Kelompok Wanita Tani( Ervinawati dkk, 2015).

Tujuan pengabdian dilaksanakan untuk mengatasi permasalahan asalah yang dihadapi oleh KWT kenanga meliputi pemanfaatan lahan pekarangan belum optimal sebagai lahan penghasil pangan keluarga, untuk mengolah hasil panen menjadi variasi olahan pasca panen dan memperluas pemasaran. penataan administrasi kelompok yang diterapkan pada KWT Kenanga.

Untuk meningkatkan ketrampilang anggota kelompok wanita tani kenanga sehingga perlu dilakukan pelatihan dan pendampingan agar dapat digunakan dalam peningkatan produktifitas anggota kelompok.

\section{METODE}

Lokasi pelaksaan Abdimas dilakukan KWT Kenanga Desa Gunung Salak , Kecamatan Selemadeg Kabupaten Tabanan. Yang berlangsung selama satu tahun. Metode yang diterapkan untuk mencapai pemecahkan permasalahan ini adalah metode tindakan dan pembelajaran yang partisipatif yang dikenal sebagai metode PALS (participatory action and learning system). meliputi: Tahap persiapan yang pelatihan dan pendampingan keterampilan pengolahan makanann berbahan dasar beras dan non beras. Monitoring administrasi KWT. Metode dalam pelaksanaan dalam bidang produksi yaitu Melaksanakan pre tes kegiatan pendampingan produksi. Melaksanakan pendampingan dan pelatihan oleh TIM Pengabdian dari Unmas Denpasar. Melaksanakan post tes setelah pendampingan dilaksankan. Mengevaluasi rangkaian kegiatan KWT Kenanga dan Evaluasi pendampingan.

Metode dalam bidang manajemen melaksanakan pendampingan dan pelatihan administras dan manajemen, mengevaluasi rangkaian kegiatan KWT Kenanga dan Evaluasi pendampingan 
Ni Putu Sukanteri, Putu Fajar Kartika Lestari, I Made Suryana. Program Abdimas KWT

Tabel 1. Indicator keberhasilan kegiatan

\begin{tabular}{|c|c|c|c|}
\hline No & Indikator & $\begin{array}{l}\text { Sebelum } \\
\text { Abdimas }\end{array}$ & $\begin{array}{l}\text { Pencapaian setelah } \\
\text { kegiatan Abdimas. }\end{array}$ \\
\hline 1 & $\begin{array}{l}\text { Peningkatan pengetahuan dan } \\
\text { ketrampilan }\end{array}$ & $\begin{array}{l}\text { Mengolah hasil panen } \\
\text { hanya di rebus dan di } \\
\text { kukus }\end{array}$ & $\begin{array}{l}\text { Mengerti } \\
\text { teknologi } \\
\text { hasil panen }\end{array}$ \\
\hline 2 & $\begin{array}{l}\text { Peningkatan hasil produksi } \\
\text { usahatani }\end{array}$ & Usahatani monokultur & $\begin{array}{l}\text { Melaksanakan system } \\
\text { tumpeng sari }\end{array}$ \\
\hline 3 & Peningkatan administrasi & $\begin{array}{l}\text { Belum punya dokumen } \\
\text { administrasi }\end{array}$ & $\begin{array}{lr}\text { Telah } & \text { memiliki } \\
\text { dokumen } & \text { administrasi } \\
\text { kelompok } & \end{array}$ \\
\hline 4 & Peningkatan minat & $\begin{array}{ll}\text { Kurang berminat } & \text { pada } \\
\text { pengolahan } & \text { hasil } \\
\text { pertanian } & \end{array}$ & $\begin{array}{l}\text { Peningkatan minat } \\
\text { terhadap pengolahan } \\
\text { hasil pertanian }\end{array}$ \\
\hline
\end{tabular}

\section{HASIL DAN PEMBAHASAN}

\section{Mengelola Lahan Pekarangan Melalui Dalam Upaya Mengoptimalkan Pangan Keluarga}

Sistem Pertanian Tumpang Sari merupakan salah satu pertanian alternative untuk memanfaatkan lahan pekarangan untuk menghasilkan komoditas yang dikembangkan. Dengan adanya pormula ditempuh dengan pembinaan dan intensifkan usahatani yang berlangsung dengan tepat, maka kemampuan kelompok akan meningkat dengan sendirinya, dalam pelaksanaan kelas di lapangan melalui penanaman hortikultura, pembibitan dan penyebaran pemeliharaan serta kerjasama antara anggota kelompok.

Pengelolaan lahan sempit dengan melakukan kegiatan budidaya tanaman buah memberikan manfaat yang besar bagi peningkatan produktivitas lahan (Rahmansyah Dermawa,2017)
Bidang kegiatan yang dilakukan kelompok menyangkut aspek teknis dilakukan sebagai berikut: (1).Pemilihan benih dan penyerahan benih kepada KWT Kenanga meliputi benih cabai, tomat, jagung, gemitir, terong. (2). Pola tanam di lingkungan lahan KWT kenanga melalui demplot dan sebagaian di lokasi lahan milik anggota kelompok masing -masing. Pemeliharaan tanaman yang telah di usahakan. Komoditas yang ditanam merupakan komoditas yang dapat dimanfaatkan untuk konsumsi keluarga maupun dapat dipasarkan dalam upaya meningkatkan pendapatan keluarga. Adapun tanaman yang ditanam yaitu tomat, cabai, gemitir dan sayur-sayuran.

Meningkatkan motivasi wanita dalam memperbaiki kualitas hidup dan kemandirian dalam keluarga dengan mengoptimalkan pekarangan dengan budidaya sayuran organic berbasis kearifan lokal dan berkelanjutan ) 

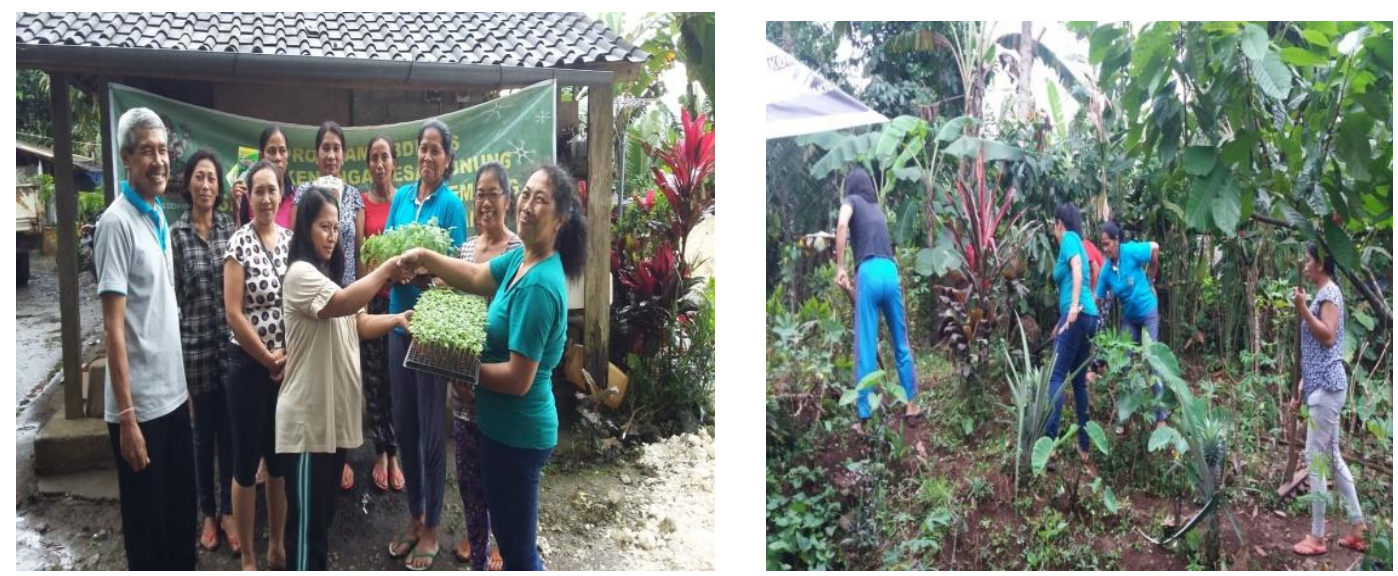

Gambar 1. Penyerahan bibit hortikultura dan penanaman bibit dilahan kelompok
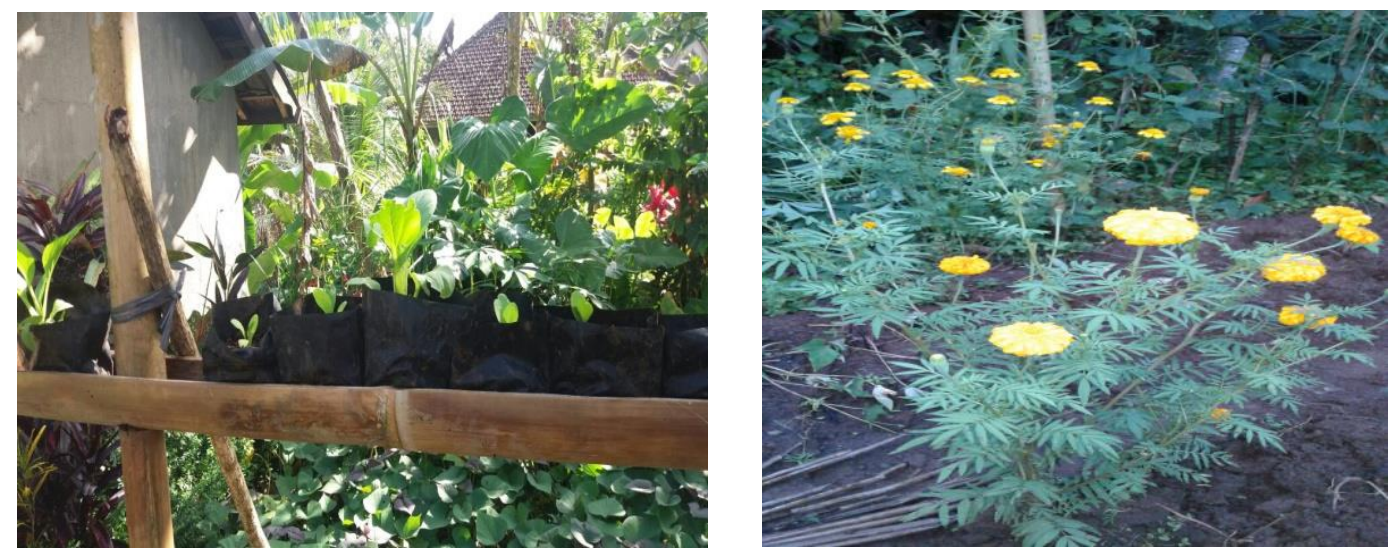

Gambar 2. Pemanfaatan pekarangan sebagai lahan usahatani.

Pembangunan ketahan pangan dilaksanakan untuk memenuhi kebutuhan dasar manusia yang memberikan manfaat secara adil dan merata berdasarkan kemandirian, dan tidak bertentangan dengan keyakinan masyarakat. Mengacu pada Peraturan Pemerintah No 22 Tahun 2009 mengenai Percepatan Penganekaragaman Konsumsi Pangan (P2KP), (Wulandari, 2018)

Pada KWT Kenangan telah dilakukan pengelolaan lahan pekarangan dengan menanam berbagai jenis komoditas yang menjadi kebutuhan keluarga dengan system tumpeng sari. Teknik ini dilakukan setelah pendampingan terhadap KWT.

Selain menanam komoditas pada lahan pekarangan keluarga, anggota KWT juga mengelola usahatani pada lahan sawah yang mayoritas menanam padi dan lahan tegalan yang menghasilkan kelapa, ketela, ubi dan talas. Seluruh hasil pertanian dimanfaatkan untuk kesejatraan keluarga, baik dikonsumsi langsung mauoun di jual kembali. Sehingga peran anggota kelompok tani tidak hanya pada usahatani kecil tetapi pada pertanian.

Pada system pertanian lahan sawah, wanita tani turut serta mengelola lahan pertanian, dari menyiapkan lahan sawah untuk ditanami padi, selanjutnya menanam padi, bahkan sampai panen dan pengolahan pasca panen( sukateri, 2017)

\section{Meningkatkan ketrampilan dan Kemampuan KWT Kenanga mengolah hasil pertanian.}

Kelompok Kenanga merupakan salah satu kelompok wanita tani yang mempunyai kegiatan usahatani hortikultura. Komoditas yang banyak dibudidayakan yaitu padi, singkong, keladi, pisang dan ubi jalar. Hasil panen yang dihasilkan biasanya hanya di rebus atau di kukus. Melalui kegiatan abdimas, anggota KWT Kenanga di ajak untuk melihat potensi yang mampu di hasilkan dari pengolahan pasca panen singkong, pisang maupun talas tersebut, adapun pelatihan yang dilakukan yaitu 
mengolah ubi ungu, ketela maupun keladi menjadi olahan menjadi bolu kukus, cake maupun gorengan, pengolahan pasca panen dapat meningkatkan nilai tambah prduk pertanian yang dihasilkan oleh masyarakat di Desa Gunung Salak yang sebelumnya hanya dikonsumsi dalam keluarga, namun setelah dilakukan pelatihan ini, anggota KWT telah mampu memasarkan produk olahan hasil panen dalam bentuk bolu kuku ubi ungu, cake keladi kuning, dan kue putri beras kelapa.

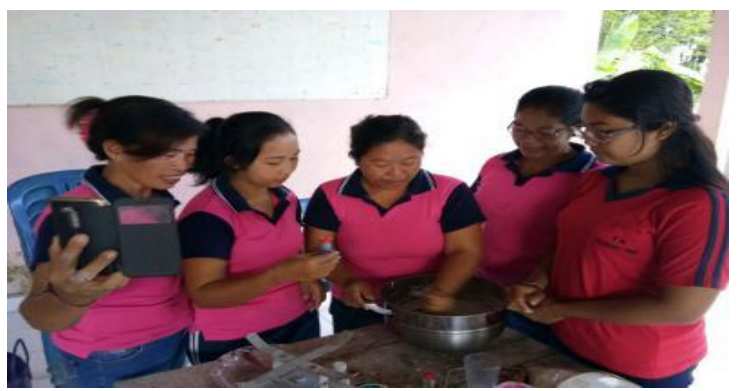

Gambar 1. Dokumentasi pelatihan mengolah kue berbahan non beras.

\section{Pelatihan Pengelolaan administrasi Kelompok}

KWT Kenanga beranggotakan ibu rumah tangga yang mempunyai kegiatan sebagai petani yang bergabung untuk melakukan kegiatan secara bersama. Sejak berdiri KWT Kenanga beberapa kegiatan telah dilakukan seperti arisan, pembudidayaan tanaman hortikultura di lahan kelompok dan di lahan masing masing anggota. Namun sepanjang perjalanan KWT Kenanga belum mempunyai kelengkapan administrasi kelompok.

Setelah dilakukan program abdimas pada KWT Kenanga, kelompok telah dibina dan dilatih dalam manajemen kelompok dan melengkapi administrasi kelompok dengan dokumen administrasi yang diperlukan seperti, buku tamu, buku kegiatan kelompok, buku kas kelompok dan beberapa dokumen kelompok yang lain seperti catatan

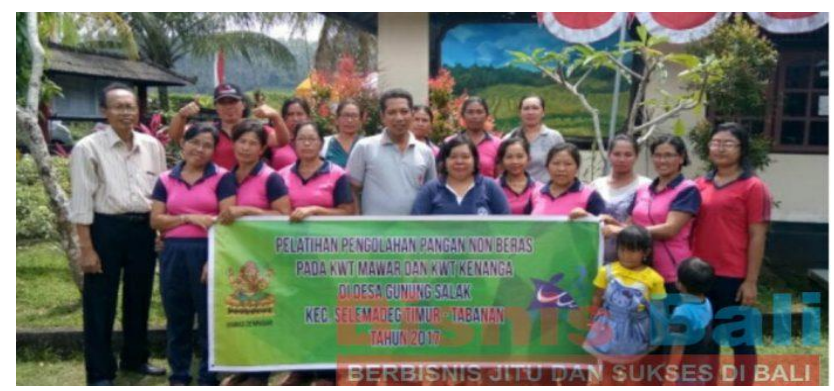

Gambar 2. Anggota pada saat Pelatihan pada KWT Kenanga

administrasi kegiatan usaha dagang yang dilakukan oleh kelompok.

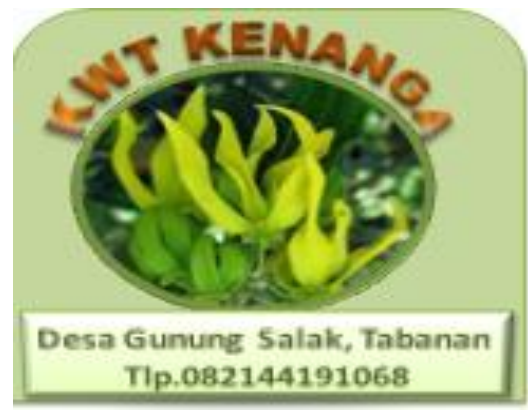

Gambar 3. Pembuatan logo pada KWT Kenanga

Pelaksanaan Kegiatan Abdimas Pada KWT Kenanga 
Tabel 2. Perkembangan KWT Kenanga Sebelum dan setelah dilaksanakan ABDIMAS

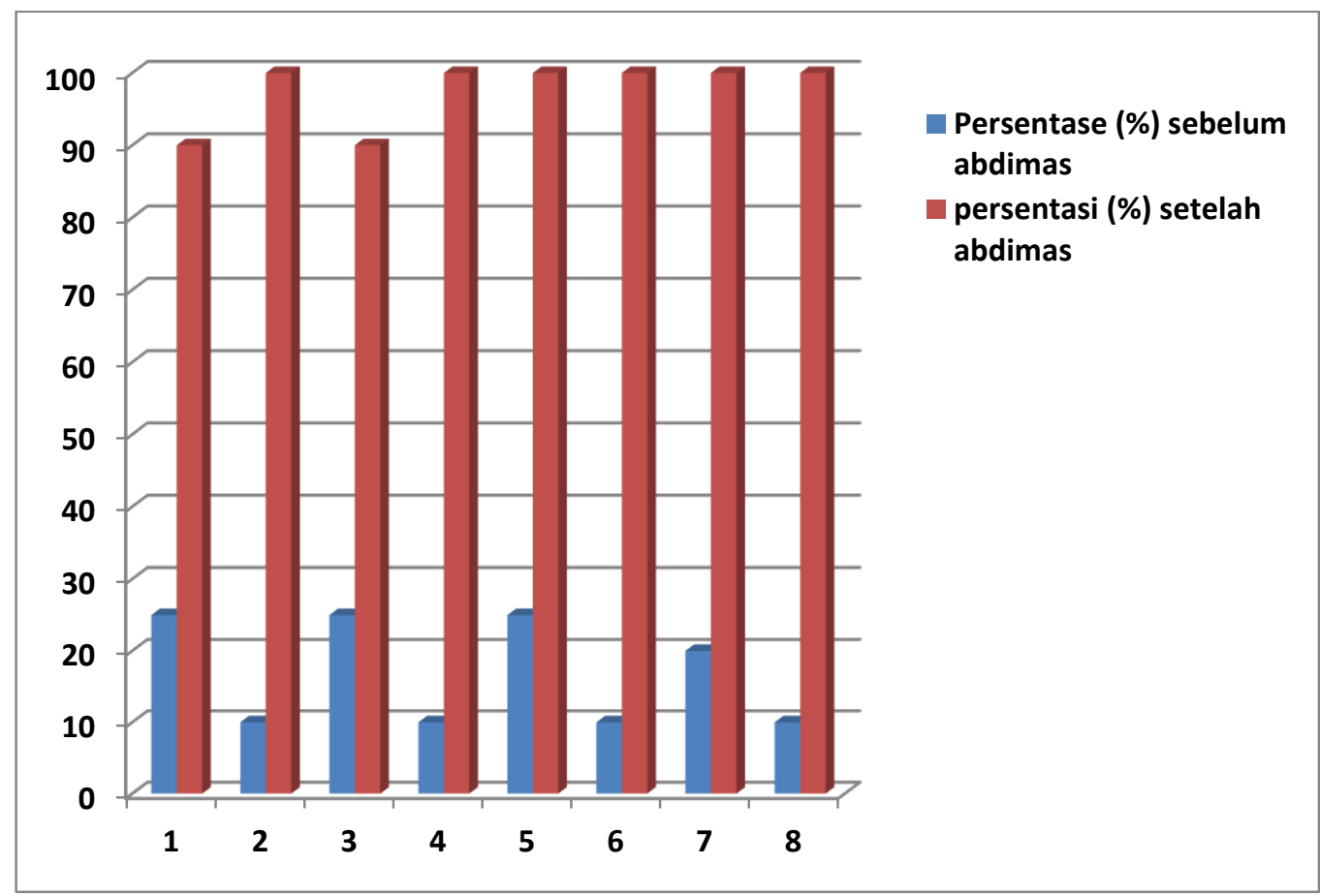

Adapun kegiatan yang telah dikelola oleh tim Abdimas pada KWT Kenanga yaitu aktifitas KWT kenanga, pertemuan anggota KWT, Pengelolaan usahatani kelompok, pelaksanakan pemasaran dan pengelolaan produk, komoditas yang ditanam, kegiatan arisan kelompok, agenda KWT dan pengolahan produk pasca panen yang dilakukann pada KWT Kenanga, kegiatan yang telah dilakukan dapat dilihat pada tabel 2 di atas.

Evaluasi dan pemecahan masalah dilakukan pada setiap pertemuan yaitu seminggu sekali untuk kumpul bersama, kegiatan arisan diakukan setiap bulan sekali. Evaluasi yang dapat dilakukan untuk kegiatan KWT Kenanga yaitu perluasan lahan untuk penanaman komoditas hortikultura yang telah di usahakan, dan menciptakan pupuk yang bisa dihasilkan dari lingkungan KWT Kenanga untuk pemupukan komoditas yang ditanam. Sehingga biaya produksi yang dikeluarkan oleh KWT disa di tekan.

\section{SIMPULAN DAN SARAN}

Kagiatan abdimas yang dilakukan di KWT kenanga Desa Gunnung Salak, Kecamatan Selemadeg Timur, Kabupaten Tabanan yaitu: (1) KWT Kenanga hanya mengolah hasil panen sepertii pisang, ubi , ketela dan talas dengan cara direbus atau di kukus, namun setelah dilakukan pelatihan melalui program Abdimas anggota KWT Kenanga telah mempunyai ketrampilan mampu mengolah hasil panen menjadi beberapa variasi olahan seperti bolu kukus, kue putu, dan variasi cake bahan baku dari hasil panen tersebut; (2) Program Abdimas pada KWT Kenanga meningkatkan ketrampilan anggota dalam bidang ketrampilan pemanfatan dan pengelolaan lahan pekarangan sebagai usahatani secara tumpeng sari dalam penyediaan pangan keluarga; (3) Program Abdimas pada KWT Kenanga telah melaksanakan pengelolaan kelompok yang tertata secara administrasi. Dokumen pengelolaan kelompok sudah ada dan berjalan.

Disarankan kepada anggota KWT Kenanga untuk terus melakukan peningkatan kemampuan dalam mengolah hasil pertanian dan mengembangkan daerah pemasarakan agar produk dapat dipasarkan dalam jaringan pemasaran yang lebih luas.

\section{DAFTAR RUJUKAN}

Ervinawati, V., Fatmawati. dan Indri, E. L. 2015. Peranan kelompok wanita tani perdesaan dalam menunjang 
Ni Putu Sukanteri, Putu Fajar Kartika Lestari, I Made Suryana. Program Abdimas KWT

pendapatan keluarga. Jurnal Penelitian Mahasiswa Ilmu Sosial Universitas Tanjungpura

Minarni, Endang, 2017. Pemberdayaan kelompok wanita tanimelalui optimasi pemanfaatan pekarangan dengan budidya sayuran organic dataran rendah berbasis kearifan lokal dan berkelanjutan. Jurnal pengabdian dan pemberdayaan masyarakat.. issn: 2549-8347. Volume 1. No.2. 2017.

Rahmansyah dermawan, ifayanti ridwan, hari iswoyo, cri wahyuni brahmi yanti, Pemberdayaan Kelompok Wanita Tani (kwt) melalui Bimbingan Teknis Budidaya Melon di Kota Makassar, Jurnal Dinamika Pengabdian, vol 2, no 2, 2017.

Saptaningsih,Sumarmi. 2009. Pengaruh Pendapatan Asli Daerah, Dana Alokasi Umum dan Dana Alokasi Khusus Terhadap Alokasi Belanja Modal Daerah Kabupaten/Kota di Provinsi D.I.Yogyakarta. Akmerupa UPY, Vol 4, 2009
Suwitaningrum, N., 2013. Kelembagaan KelompokWanita Tani (KWT) Pengolah Hasil Pertanian (Studi pada KWT di Kota Salatiga). UKSW, Salatiga.

Sukanteri, 2018, Wanita Tani dalam Eksistensi Budaya Subak Penerbit: Plantaxia, Tahun: 2018

Sutjirta, 2015

Soekartawi, 2011. Ilmu usahtani dan penelitian untuk usahatani kecil, UI Press. Jakarta. 2011

Wulandari, N. (2018). Strategi Pengembangan Kelompok Wanita Tani pada Optimalisasi Lahan Pekarangan di Desa Wonogiri. Efficient: Indonesian Journal of Development Economics, 1(1), 3443. 